\title{
Léxico, leitura e livro didático: uma tríade em análise no ensino do português
}

\author{
Ana Flávia Torquetti Domingues Cruz \\ Universidade Federal de Minas Gerais (UFMG), Belo Horizonte, Minas Gerais, Brasil \\ anaflavia_torquetti@hotmail.com
}

DOI: http://dx.doi.org/10.21165/el.v45i2.732

\begin{abstract}
Resumo
Diante das poucas evoluções percebidas no tratamento dado ao léxico em materiais didáticos nas últimas décadas, o que repercute negativamente nas habilidades de leitura a serem desenvolvidas por alunos-leitores, o presente artigo visa a explorar possibilidades de se aliar os ensinos de léxico e de leitura a partir de exercícios sobre sinonímia encontrados na obra destinada ao $6^{\circ}$ ano do Ensino Fundamental da coleção de livros didáticos de português intitulada "Para viver juntos". Apoiando-se, assim, na Linguística Textual e nas pesquisas realizadas por Travaglia (2002), Antunes (2003), Dell'Isola (2005), Ferraz (2006) e Elias e Koch (2012), este trabalho pretende contribuir para o desenvolvimento das competências linguísticas de alunos brasileiros.
\end{abstract}

Palavras-chave: competência lexical; ensino; leitura; livro didático.

Lexicon, Reading and Textbooks: a Triad under Analysis in the Teaching of Portuguese

\begin{abstract}
The few developments perceived in the treatment of the lexicon in teaching materials in recent decades has had negative repercussions on the reading skills to be developed by students-readers. In view of this fact, this article aims to explore possibilities to combine the teaching of the lexicon and the teaching of reading from exercises on synonymy found in "Para viver juntos", a textbook for the $6^{\text {th }}$ year of elementary school which belongs to a collection of textbooks for teaching Portuguese. Thus, based on Textual Linguistics and on researches made by Travaglia (2002), Antunes (2003), Dell'Isola (2005), Ferraz (2006) and Elias e Koch (2012), this work intends to contribute to the development of language skills of Brazilian students.
\end{abstract}

Keywords : lexical competence; teaching, reading; textbook.

\section{Introdução}

Estudiosos da Linguística Aplicada que se ocupam do ensino do português, bem como testes e provas realizados pelo Sistema de Avaliação da Educação Básica (SAEB), têm diagnosticado e discutido o fato de que são muitos os alunos brasileiros deficitários no desenvolvimento de habilidades de leitura. Outra deficiência desses estudantes se relaciona ao ensino do léxico. A importância das palavras para as relações sociais é evidente e, por isso, é preocupante o diagnóstico feito por estudos que apontam no livro didático de português (doravante LDP), material muito frequente nas salas de aula, uma insistente carência no ensino do léxico. Cruz (2015) discute a relação íntima que se verifica entre o descompromisso com um processo de ensino-aprendizagem de leitura crítica com o também negligenciado desenvolvimento das competências lexicais dos alunos brasileiros. A interseção de leitura e de léxico, respaldada pela evidência de que os textos verbais são compostos por palavras lexicais e gramaticais, é promotora de um 
progresso simultâneo do leitor-aluno em ambos os aspectos, assim como o descompasso em seu ensino ou, mais grave, a falta de um deles, repercute negativamente em toda e qualquer leitura que o aluno vier a fazer. Desse modo, justifica-se a proposta de buscar alternativas para um ensino que promova, igual e simultaneamente, as competências lexicais e leitoras dos estudantes brasileiros.

A dependência existente entre o ensino do léxico e da leitura é também reconhecida pelos PCN (Parâmetros Curriculares Nacionais, Brasil, 1998). Primeiro, porque o documento oficial compreende a complexidade inerente à leitura, a qual não é entendida como um ato, mas como um processo reflexivo, intelectual. Segundo, porque, ao instruir como o léxico deve ser abordado pela escola, ele traz à tona a necessidade de articulá- lo ao ensino do texto. Nesse contexto, o LDP foi selecionado como corpus desta análise, devido à sua relevância no cenário educacional brasileiro hoje. A importância desse material é comprovada pelo fato de que, conforme Ramos (2000), o Governo Federal se tornou o maior comprador do país de livros didáticos na década de 1980, o que originou políticas públicas sérias, a fim de garantir a sua qualidade, como é o caso do Programa Nacional do Livro Didático (PNLD). Desse modo, revisar insistentemente esses livros, o que é feito por meio do PNLD e de pesquisas acadêmicas, tende a ser uma maneira de buscar melhorias na educação, objetivando averiguar se esses materiais didáticos estão em consonância com os PCN e com as propostas didáticas desenvolvidas e aprimoradas no meio acadêmico. Perante, portanto, a situação supracitada, a proposta deste artigo também se destina à formação docente, uma vez que serão sugeridas adaptações de alguns dos exercícios observados na obra didática destinada ao $6^{\circ}$ ano do Ensino Fundamental "Para viver juntos".

As propostas de aperfeiçoamento dos exercícios observados são realizadas a fim de sublinhar que o professor capacitado técnica e criticamente deve agir de maneira autônoma diante do material didático que utiliza, ou seja, busca-se incentivar o docente a ser o norte dos estudos que propõe, estimulando-o a utilizar o LDP e a elaborar materiais autorais de maneira consciente, o que aperfeiçoaria a sua prática e tornaria mais produtivo o desenvolvimento da competência lexical de seus alunos.

\section{Léxico, leitura e LDP: problemáticas no ensino de língua portuguesa nas escolas brasileiras}

Esta análise assume a percepção de que ler é uma atividade processual, complexa e, ao adotar essas noções, emerge a necessidade de se estudar estratégias a fim de ensinar, efetivamente, a ler. A leitura deve ser assimilada como compreensão, ou seja, para que o aluno de fato acesse as informações de um texto, espera-se que ele seja habilidoso em vários aspectos e que ele disponha de estratégias para assimilar o conteúdo em questão, sendo requeridos, para isso, os seus conhecimentos intra e extralinguístico. Cafieiro e Coscarelli (2013) amparam que a leitura é um processo de construção e de reconstrução de sentidos a partir das experiências de mundo do leitor. Segundo as autoras, para ler, é preciso "perceber, analisar, sintetizar, relacionar, inferir, generalizar, comparar" (CAFIEIRO; COSCARELLI, 2013, p.16). Em consonância com a complexidade supracitada, é necessário emergir a ideia pouco desenvolvida pelas escolas de que o léxico, como indica Ferraz (2006), devido à sua relação íntima com a cultura e com a sociedade, é o elemento dos idiomas de maior impacto extralinguístico, o que é reforçado por Biderman (1996), que aponta para o fato de ele ser responsável pela estocagem das significações e dos significantes da linguagem humana. Outro aspecto relevante aponta para o fato de as palavras terem como característica marcante o fenômeno da 
multissignificação, isto é, seus significados não são estanques, mas plásticos, sujeitos aos contextos em que se aplicam e aos falantes que os utilizam. As regularidades internas desse sistema aberto e os seus modos específicos de funcionamento, como a construção de novas palavras, como prefixos, sufixos, radicais simples ou complexos, ressaltados por Correia (2011), assim como o modo como as palavras se articulam, promovendo, a partir disso, sentidos mais complexos, caracterizam-no.

Tendo em vista, portanto, a complexidade inerente tanto ao léxico quanto à leitura, é preciso esclarecer que, ao se tratar do seu ensino, é preponderante versar, respectivamente, sobre competência lexical e sobre competência leitora, isto é, sobre a capacidade que um usuário de determinada língua deve ter de utilizar as palavras efetivamente, bem como de reconhecê-las e de compreendê-las nas situações comunicativas que vivenciar, "de usar a língua de modo adequado a cada situação de interação comunicativa, obtendo os efeitos de sentido desejados para a consecução de intenções comunicativas específicas" (TRAVAGLIA, 2002,p. 136). Quando objetiva-se, no processo de ensino-aprendizagem, alcançar esses propósitos e se reúne estratégias, bem como se reflete sobre tal processo constantemente, desenvolve-se a competência linguística do aprendiz.

No entanto, os conceitos e sugestões acima expostos vão de encontro a como se ensina o léxico e a leitura, hoje, na educação brasileira, já que, definitivamente, a sua complexidade não é reconhecida. De fato, os LDP ainda ostentam noções de língua estanque. Antunes (2012), por exemplo, ressalta que a natureza do ensino do léxico ainda é respaldada por percepções puramente gramaticais, como se apenas os aspectos morfológicos caracterizassem os itens lexicais, desconsiderando-se, assim, a função ímpar das palavras na arquitetura de um texto, o que, evidentemente, repercute mal nas habilidades leitoras. A autora acima mencionada ainda mostra que os exercícios sobre léxico encontrados nos LDP quase sempre se resumem a definições ou a explicações por sinonímia, ou seja, na prática, à língua não se articulam adjetivos como variada, multifacetada, heterogênea. Nesse sentido, Marcuschi (2003) declara que parte importante dos LDP não considera que as línguas são fenômenos sócio-históricos, característica que as torna semanticamente opacas, aspecto esse que, mais uma vez atrela, necessariamente, a habilidade de interpretar textos à competência lexical. Outro estudo que contribui para a compreensão de como léxico e leitura são articulados nos LDP é o de Calçada (1990, p. 293). A autora mostra que as coleções didáticas de português se estruturam de modo semelhante, apresentando lições que trazem um texto para leitura, exercícios de vocabulário do texto, interpretação de texto, atividades de gramática e redação, além de quase todas oferecerem também um glossário com algumas das palavras utilizadas nas lições. Ademais, ela afirma que

Se atentarmos para os aspectos teórico-metodológicos, defrontar-nos-emos, logo de início, com a falta de delimitação de um vocabulário fundamental, a ser dominado pelos alunos durante o processo ensino-aprendizagem de sua língua. Além de não haver previsão de um léxico básico e de sua ampliação gradual, inexiste qualquer preocupação pela fixação e uso de palavras estudadas para a compreensão de textos. Após realizados os exercícios, as unidades linguísticas trabalhadas, por seleção intuitiva do autor, não são retomadas em outras lições. A aquisição vocabular, se ocorrer, torna-se então um fato meramente acidental. Assim, os fatores psicológicos como a motivação, a atenção, a percepção e a memorização das palavras, indispensáveis ao bom desempenho do locutor na seleção vocabular e posterior elaboração do seu discurso, não são prestigiadas. (CALÇADA, 1990, p. 295) 
Assim, os estudos de Calçada (1990) indicam um ponto preocupante a respeito do ensino do léxico: inexistem, na maioria das vezes, estratégias colocadas conscienteme nte, as quais visariam ao efetivo desenvolvimento lexical do estudante. Em acordo com essa autora, um estudo de Marcuschi (2003) sinaliza que, embora grande parte dos autores de LDP demonstrem acreditar ser importante o trabalho com a compreensão textual, posto que exercícios dessa natureza são prosaicos em tais obras, também faltam, no que se refere à interpretação textual de modo mais genérico, recursos conscientes para a promoção da competência leitora. Segundo o autor, a maioria das questões de compreensão são indagações genéricas que não dependem do texto para serem respondidas. Ademais, ironia, metáfora, análise de intenções e outros aspectos relevantes são desconsiderados pela maioria das atividades de compreensão, o que dificulta $o$ desenvolvimento de reflexões críticas e da expansão de sentidos. Em seu trabalho, Marcuschi (2003) avaliou 2.360 perguntas, e, das suas análises, depreende-se que as perguntas subjetivas, muito presentes nos materiais didáticos de língua materna, além de raramente demonstrarem capacidade de avaliar o senso crítico e a capacidade argumentativa do aluno, pouco contribuem para o desenvolvimento da sua competência lexical. Como conclusão de seu estudo, o autor definiu que as perguntas que se baseiam exclusivamente nas superfícies do texto, sendo a maioria delas as de cópia (70\%), são as que definitivamente caracterizam o LDP, uma realidade que confirma o que muitos estudiosos do ensino de língua materna já atestaram: a leitura não é bem desenvolvida por meio das atividades propostas pelos LDP, muito embora os textos selecionados sejam, em grande parte das vezes, excelente fonte para que isso ocorra.

É evidente que o que agrava ainda mais o contexto acima discutido são as raras oportunidades de se realizar reflexões complexas, as quais envolvem inferência ou raciocínio crítico, já que, apesar de serem essas as questões mais expressivas para o desenvolvimento das habilidades lexicais e leitoras, elas correspondem a apenas um décimo de todas as atividades analisadas, segundo Marcuschi (2003). Assim, perguntas óbvias, que não valorizam a capacidade intelectual dos estudantes, são recepcionadas por eles com desinteresse e até mesmo com desprezo. Andrade e Santos (2010), em pesquisa que visou a elencar os tipos de exercícios sobre léxico que se verifica nos LDP, observaram que, dos 213 exercícios identificados como abordadores do léxico, 169 vinculavam-se aos gêneros textuais, enquanto 44 não o faziam, sendo esses últimos encontrados nas seções de estudos linguísticos. De maneira análoga ao que se verificou na pesquisa supracitada, os resultados desta revelam que a maioria dos exercícios observados compreendem como palavras de significados estáticos, desconsiderando, desse modo, o contexto em que elas se evidenciam. Confirmando isso, com comandos como "pesquise no dicionário ou consulte o dicionário", isto é, a maioria das atividades analisadas não considera a palavra em uso, mas o seu significado no dicionário, renegando a coesão que o arranjo dos vocábulos promove no texto. Dialogando com esse cenário, Teixeira (2009, p. 67) afirma que há "pouca criatividade pedagógica no tratamento do vocabulário nos manuais didáticos". A autora sublinha o fato de que não é problema trabalhar, na relação texto e léxico, antonímia e sinonímia, mas mostra-se problemático e ineficiente fazê-lo por meio de automatismos, o que se verifica em pesquisas como a exposta acima.

É perceptível que as noções supracitadas, todas elas ainda adotadas pela maioria das escolas brasileiras, é totalmente incoerente em relação aos Parâmetros Curriculares Nacionais de Língua Portuguesa (BRASIL, 1998), os quais indicam que "a Escola é um espaço de interação social onde práticas sociais de linguagem acontecem e se circunstanciam" (1998, p. 22). É importante dizer, porém, que, para além do LDP, um 
dos fatores que mais agrava esse cenário é a inércia de muitos docentes diante desse material. Isso ocorre por falta, em muitos casos, de uma formação que lhes assegure conhecimento efetivo de conceitos que devem ser transpostos para a sala de aula, o que faz com que muitos profissionais sigam à risca o que traz o LDP, sem questionar, sem se posicionar, sem se sentir no direito de selecionar e até mesmo de modificar, de maneira mais adequada aos seus propósitos didáticos, os conteúdos presentes nele.

A crise da educação no Brasil, que se estende por décadas, faz emergir, consequentemente, uma crise no que se refere ao exercício docente, a qual engloba tanto os aspectos de identidade e autoestima desse profissional, quanto os relacionados à sua capacidade técnica e à sua formação, que se concretizam na hegemonia do livro didático em sala de aula, apagando a autonomia e até mesmo o senso crítico dos professores. Azeredo (2007) mostra que, quando, na década de 1960, as obras didáticas passaram a propor exercícios, tornando-se, assim, os autores desses materiais mais atuantes nas aulas do que os docentes, os quais já encaravam a crescente depreciação da profissão, os professores passaram, paulatinamente, a se verem como reféns dos seus LDP, preocupados em "esgotá-los" até o final do ano letivo, raramente utilizando materiais didáticos de outra natureza, menos ainda algum do qual sejam autores. A adoção dos livros didáticos, portanto, está perpassada por polêmicas e por incertezas quanto à necessidade e à viabilidade de seu uso, contudo a realidade dos dias atuais não pode ser negada: esse material se encontra na grande maioria das aulas ministradas em escolas brasileiras. Assim, além de apontar os equívocos (e também os acertos) trazidos por ele, é necessário promover trajetos que contribuam para que o professor consuma esse material com criticidade, tornando-se, assim, apto a adaptar conteúdos e atividades que considerar inadequados sob o ponto de vista conceitual ou mesmo contextual, avaliando, sistematicamente, a realidade e as possibilidades de desenvolvimento da competência linguística dos alunos com os quais atua. Isso evidencia que estudos destinados ao empoderamento do professor por meio de uma qualificação teórico-metodológica voltada para o ensino do léxico e da leitura contribuem para que sejam alcançados avanços no ensino do português no país.

\section{Revisão da sinonímia como estratégia para o desenvol vimento de habilidades de leitura}

O leitor, enquanto construtor de sentidos, lança mão de algumas estratégias de leitura, tais como a ativação dos conhecimentos prévios, a seleção, a antecipação, a inferência e a verificação. Tendo em vista este fato, Kleiman (1996) propõe uma abordagem eficiente e coerente com essa realidade, baseando-se no ensino de estratégias de leitura que contribuiriam, também, para o desenvolvimento das habilidades linguísticas, dentre as quais está a lexical. No âmbito dos muitos aspectos preponderantes para a interpretação de um texto, interessa a esta análise a materialidade textual associada ao conhecimento de mundo do leitor. É viável dizer que a materialidade pode ser encarada a partir de alguns pontos, tais como as características gráficas do texto, assim como os itens lexicais e gramaticais de uma língua, o que remonta o fato de que a leitura de um texto cujas palavras são, em boa parte, desconhecidas, provoca uma barreira, a qual dificulta e, não raro, inviabiliza uma interpretação de fato.

Ainda no que tange ao desenvolvimento do léxico associado ao da leitura, Leffa (2000) mostra a necessidade de se diferenciar o aprendizado incidental do intencional. O primeiro ocorre, ao longo de suas experiências sociais, com todos os falantes, os quais, nessas interações, assimilam novas unidades lexicais, isto é, trata-se de um aprendizado 
natural e não planejado. Já o segundo é proposital e, no que se refere à língua materna, só existe quando o falante passa pela escolarização, pois é por meio do ensino formal que ocorre um esforço consciente para aprender novas palavras, esforço este que apenas é eficiente se associado à leitura e à escrita. É possível elencar diversas estratégias cujos propósitos não são somente amenizar a deficiência em leitura que muitos estudantes brasileiros têm apresentado nas séries finais do ensino fundamental, mas também o fato de que isso está intimamente relacionado ao léxico individual desses alunos. Dentre elas, está a exploração das anáforas, da coesão nominal de modo mais genérico, da seleção lexical, da hiperonímia, das repetições de palavras, das paráfrases e da sinonímia. Esta última protagoniza as propostas abaixo discutidas, tendo em vista a sua recorrência nos LDP, o que não impede que ela seja relacionada às demais.

Os PCN sublinham, como enfatiza Pauliukonis (2007), que os sinônimos devem ser abordados nas aulas de língua portuguesa, expandindo o repertório lexical dos alunos, além de torná-los aptos a evitar repetições viciosas de certos vocábulos na escrita. Outro benefício dessa abordagem está no fato de que, por meio dela, os alunos se tornam mais aptos a compreender as relações entre as palavras que compõem um texto, ou seja, o impacto no desenvolvimento de habilidades de leitura é grande. Muito embora os benefícios dos sinônimos no ensino de língua portuguesa sejam significativos, a sistemática presença de exercícios sobre eles nos LDP não têm surtido os efeitos pretendidos, o que pode ser justificado, por exemplo, pelo fato de que, na maioria das vezes, nessas atividades, solicita-se que uma palavra seja substituída por outra, o que é superficial e pouco enriquecedor quando se parte do princípio de que a ideia de sinônimos perfeitos já foi descartada por diversos trabalhos acadêmicos em Linguística Aplicada. Antunes (2010) confirma a inexistência dos perfeitos ao expor que, intuitivamente, os falantes têm consciência disso quando dizem, por exemplo, que Joana não é bonita, é linda, assim como quando afirmam que Joana não está contente, está feliz. Essas correções comprovam que, ainda que sutis, os sinônimos apresentam diferenças semânticas, as quais repercutem nas suas escolhas. Essa característica da sinonímia dá margem a importantes reflexões nas aulas de língua portuguesa, e é ela, em detrimento da ideia de plena substituição, que deve ser de fato explorada.

Atrelando-se a essa proposta de sinonímia, portanto, está, como mostra Koch (2004), a seleção lexical, uma estratégia comunicativa que oferece possibilidades que se formatam ao projeto de dizer do autor de um texto. Assim, é desejável que os professores de português evidenciem para seus alunos que, ainda que algumas palavras sejam semanticamente muito próximas, há entre elas diferenças provenientes das atitudes dos próprios falantes, os quais acolhem uma gradação entre os sinônimos, apreendida nas restrições que uma palavra sofrerá em determinado contexto. Ademais, outros pontos são relevantes e tornam essas diferenças sensíveis. Seria o caso das palavras "obeso" e "gordo" que, mesmo tendo traços semânticos que as aproximam, são socialmente utilizadas em situações que se diferem. "Obeso" é admitido como o item lexical politicamente correto, porém "gordo" reforça no adjetivado um estigma. Salientar essas divergências e contribuir para que o aluno as perceba é, ao mesmo tempo, desenvolver a sua competência lexical e as suas habilidades leitoras. É, também, ensinar a ler o mundo. Antunes (2010, p. 182) evidencia esse fato ao atestar que:

Isso implica admitir que os significados das palavras andam, deslizam, movem-se, diferenciam-se, por acréscimo ou por redução dos traços semânticos. Os semanticistas são unânimes em admitir, para além dos significados conceituais das palavras, os significados afetivos que as palavras vão adquirindo ao longo do tempo. Por isso é que 
"bonito" e "lindo" não correspondem exatamente ao mesmo e, portanto, não são intersubstituíveis.

Outra ilustração interessante é a que distingue "blecaute" de "apagão", conforme demonstram Cruz e Mendes (no prelo). O termo blecaute tem sido usado no Brasil para designar o corte ou o colapso temporário do suprimento de energia elétrica em uma determinada região. Segundo o dicionário digital Caudas Aulete, o verbete "blecaute" é definido, na primeira acepção que recebe, como falta generalizada de luz em um bairro, cidade ou região. Nesse caso, a fim de corroborar os aspectos que distanciam semanticamente as palavras supracitadas, faz-se importante imergir na história.

Cruz e Mendes (no prelo) mostram que, passado o colapso elétrico de 1965, nos Estados Unidos, o termo blecaute (blackout) tornou-se popular no Brasil, passando a designar a ausência de energia elétrica nas grandes regiões do país. Já a forma apagão foi mencionada no Jornal do Brasil (1981) em um espaço reservado a neologismos. No que diz respeito ao sentido acima mencionado de apagão, foi em 2001 que seu uso se intensificou de fato e inclusive foi, em certa medida, reformulado, tendo em vista que a população brasileira, nessa época, foi induzida a uma economia no consumo de energia elétrica, a fim de se evitar o racionamento. Assim, o uso de apagão está estreitamente ligado à crise de racionamento de energia no Brasil, a qual impôs a algumas regiões brasileiras medidas coercitivas. Em sala de aula, é relevante traçar o percurso sóciohistórico de alguns sinônimos, mostrando, por exemplo, as circunstâncias que fazem uma palavra se tornar mais popular do que o seu sinônimo, o qual costumava ser o mais produtivo, a exemplo de blecaute e de apagão. Ainda é possível evidenciar a importânc ia da mídia para a discursividade e, mais uma vez, nota-se que as palavras em questão não são sinônimos perfeitos, uma vez que, caso fossem, seria inoportuno substituir uma pela outra.

A reflexão proposta por Koch (2004) a respeito das relações de parassinonímia também se mostram uma maneira inovadora e eficaz de se trabalhar a temática em voga.

É comum que a anáfora demonstrativa apreenda o referente sob uma denominação que constitui um sinônimo mais ou menos aproximado da designação presente no co-texto, trazendo, nesse caso, informações inéditas a respeito do referente, justamente por designá-lo por um novo nome, dificilmente previsível pelo destinatário, como ocorre em (12): A polêmica parecia não ter fim. Pelo jeito, aquele bate-boca entraria pela noite adentro, sem perspectivas de solução. (KOCH, 2004, p. 51, grifo da autora)

No caso, é por meio de inferências possibilitadas pelo contexto que, no exemplo sugerido pela autora, "polêmica" e "bate-boca" tornam-se sinônimos. Koch (2004) sinaliza o fato de que nem sempre as duas denominações anafóricas utilizadas na designação de um objeto são explicitamente equivalentes, o que remete a situações em que os conhecimentos lexicais e enciclopédicos precisam ser compartilhados pelos falantes. Esse fato corrobora a relação estreita entre ensinar léxico e ensinar leitura simultaneamente. As anáforas definitórias também são discutidas por Koch (2005), as quais são muito comuns em textos de viés cientifico, em que, não raro, um termo técnico é retomado por uma palavra de uso mais comum. A autora exemplifica o fenômeno ao explicitar um texto em que a palavra "macaco" aparece como anáfora definitória de "os bugios" e "símios". Essa ilustração evidencia que, em uma aula de ciências, é possível que o professor de tal disciplina explicite a coesão nominal promovida pela escolha lexical dessas palavras, que são sinônimas, mas têm funções distintas no texto. Desse modo também se avança em termos de competência linguística. Enfim, como foi mostrado, é necessário, e possível, conquistar um ensino mais edificante ao atrelar léxico e leitura sob o viés da sinonímia. Antunes (2012, p. 78) corrobora esta posição ao dizer 
que "a principal função da sinonímia se manifesta no âmbito do texto, quando a ocorrência de uma palavra e de seu sinônimo cria e sinaliza nexos de continuidade e sinais de unidade", o que evidencia que é na materialidade textual, principalmente, que se deve ensinar a função dos sinônimos, evidenciando o nexo que sinaliza a sequência do texto. Tendo em vista, portanto, as possibilidades supracitadas e a frequência de exercícios sobre sinônimos verificada em LDP, optou-se, neste artigo, por analisar os exercícios que exploram a sinonímia na obra destinada ao $6^{\circ}$ ano do Ensino Fundamental da coleção didática "Para viver juntos". Posteriormente à análise, objetivou-se evidenciar possibilidades de reformulação dos exercícios observados, a fim de indicar possibilidades de melhorias nessas atividades para alcançar resultados mais alinhados com a discussão aqui realizada.

\section{A sinonímia em "Para viver juntos": análises e propostas}

A coleção didática destinada ao EF II denominada "Para viver juntos" (2012), cujos autores são Cibele Lopresti Costa, Greta Marchetti e Jairo J. Batista Soares, apresenta como ponto forte, segundo o PNLD (2014), atividades de leitura, as quais adotam uma perspectiva textual e discursiva na abordagem dos conhecimentos linguísticos. Ainda sobre a leitura, o documento oficial sinaliza que essa habilidade é ancorada no estudo dos gêneros textuais, além de afirmar que as questões de interpretação textual capacitam o aluno, progressivamente, a se aprimorar nas habilidades supracitadas, tendo em vista o fato de que são verificadas atividades que vão da ativação de conhecimentos prévios à inferência de sentidos globais. O PNLD (2014) justifica a indicação da leitura como ponto forte da coleção pela quantidade, pela variedade de textos explorados, bem como pelo volume de seções voltadas para ela. Quanto a esses aspectos, é válido dizer que existe sintonia entre o discurso apresentado no manual do professor e o que o PNLD (2014) elabora. No que se refere ao trabalho com o léxico, no entanto, o programa não cita seção específica, o que se confirmou na análise do material voltado ao $6^{\circ}$ ano. Esse fato reforça o que pesquisas acadêmicas sobre o ensino do léxico têm demonstrado: a sua abordagem, definitivamente, não é uma das prioridades da grande maioria dos LDP.

Em trabalho anterior, Cruz (2015) analisou, a partir de parâmetros semelhantes aos utilizados para a análise do volume do $6^{\circ}$ ano de "Para viver juntos", a coleção didática "Projeto Teláris - Português" (2012). O que distancia as duas análises é, principalmente, o fato de que, em "Projeto Teláris - Português", a autora não se ateve à sinonímia, observando, também, outras estratégias de leitura vinculadas ao léxico. Em ambas as observações foram verificadas, somente, as seções de interpretação de textos, tendo em vista o interesse pela associação entre léxico e leitura. Ademais, em ambos os casos buscou-se verificar a complexidade dos enunciados das questões, bem como se elas carregam, efetivamente, uma proposta textual. Concluiu-se a partir da apreciação de "Projeto Teláris - Português", que há indícios significativos de avanço no ensino do léxico, já que em todos os capítulos dos quatro volumes da coleção, nas seções denominadas "Interpretação do texto", há questões que o abordam, relacionando-o à leitura. Outro avanço trazido por esses LDP é o fato de eles diversificarem bastante as estratégias de ensino, extrapolando as relações de sinonímia, as quais, como dito anteriormente, tendem a ser onipresentes nessas obras. A maneira como isso se realiza, no entanto, é, muitas vezes, equivocada, já que parte expressiva dos exercícios ou solicitam transcrições ou localizações de unidades lexicais. Desse modo, tomando como referência as observações de Marcuschi (2003), em "Projeto Teláris - Português", são predominantes questões de cópia, cujos comandos são copie, retire, aponte, indique, transcreva, complete, assinale, identifique. Também são expressivas as atividades 
objetivas, em que a interpretação é entendida como decodificação. No que se refere especificamente ao material destinado ao $6^{\circ}$ ano da coleção, os exercícios que abordam a sinonímia são numerosos, porém a sua elaboração poderia ser melhor, já que grande parte deles se atêm a relações óbvias, emergindo, desse ponto, o seu marcante viés estruturalista. Ao todo, nesse livro, foram contabilizados 53 exercícios que aliam o léxico à leitura. A obra "Para viver juntos" voltada ao $6^{\circ}$ ano está ainda mais defasada nos aspectos observados se comparada à "Projeto Teláris - Português". Nos nove capítulos do LDP, na seção de interpretação de textos, verificaram-se apenas 26 questões que, em alguma medida, demonstram objetivar o desenvolvimento da competência lexical do aluno, sendo sete delas sobre sinonímia. Abaixo, encontra-se uma dessas atividades, a qual foi escolhida para esta análise por ser bastante representativa das demais. Trata-se de um exercício sobre um trecho da obra Robinson Crusoé, considerada, no livro, um romance de aventura.

Releia.

"Sexta-feira andava pela praia, à cata de tartarugas. Voltou correndo, apavorado. [...] Também me assustei. Não contava com o ine sperado: os selvagens não vinham à ilha no tempo das chuvas. Espiei-os do alto da paliçada, com os binóculos. Desembarcavam muito próximos do meu castelo, logo depois do ribeirão. O perigo nunca fora tão iminente..."

Qual ideia as palavras destacadas sugerem ao leitor?

(Para viver juntos, $6^{\circ}$ ano, p. 19)

O exercício transcrito acima apresenta problemas que também foram observados na coleção "Projeto Teláris - Português", o que pode indicar um padrão indesejável no tratamento dado à sinonímia nos LDP atuais. Na atividade, observa-se que é dado um tratamento superficial ao tema, uma vez que não é requerida uma habilidade complexa, como explicar ou justificar. Não é exigida do aluno, assim, capacidade para fazer inferências, uma vez que o problema pode ser solucionado a partir de simples indicações de sinônimos de cada item lexical, isto é, não houve exploração do campo semântico, da cadeia coesiva proporcionada pela escolha lexical, tampouco são solicitadas reflexões acerca da escolha de uma palavra em detrimento de seu sinônimo. Tudo isso leva a crer que tal atividade, a qual, como dito anteriormente, espelha as demais da coleção voltadas para a sinonímia, ainda se apoia na defasada noção de sinônimos perfeitos e, por isso, não haveria, inclusive, necessidade do contexto para realizar o que foi proposto. A fim de amenizar essas lacunas, sugere-se que o professor que atuar com esse material, consciente da sua autonomia, realize modificações simples na questão, mas que promovam as habilidades necessárias em relação às almejadas competências lexical e leitora. Abaixo está uma das muitas possibilidades de reformulação da atividade em foco.

(01) Releia.

"Sexta-feira andava pela praia, à cata de tartarugas. Voltou correndo, apavorado. [...] Também me assustei. Não contava com o inesperado: os selvagens não vinhamà ilha no tempo das chuvas. Espiei-os do alto da paliçada, com os binóculos. Desembarcavam muito próximos do meu castelo, logo depois do ribeirão. O perigo nunca fora tão iminente..."

As palavras 'atemorizado', 'assustado' e 'horrorizado' são, em muitos contextos, sinônimos de 'apavorado'.

A) Indique qual dessas palavras melhor se adequaria ao contexto acima em uma suposta substituição da palavra 'apavorado'. Justifique a sua escolha.

B) Ordene, de acordo com a intensidade (da menor para a maior), os quatro sinônimos acima expostos. Explique a sua escolha. 
C) Comente como as palavras em destaque no trecho acima foram utilizadas a fim de criar um clima de mistério na narrativa.

A sugestão acima, ao contrário do original, visa sensibilizar o aluno para a inexistência de sinônimos perfeitos e, para além disso, busca promover uma reflexão sobre a gradação que se percebe entre sinônimos, a qual emerge o fato de que, em grupo de itens lexicais considerados semelhantes, alguns terão mais proximidade semântica entre si do que outros, o que é reforçado pelo contexto. No caso, a palavra assustado representa menos a carga emotiva de apavorado do que horrorizado, por exemplo. Pretende-se, portanto, que o aluno lance mão da sua experiência enquanto falante de língua portuguesa para compreender isso, o que demanda um esforço intelectual que, progressivamente, leva o usuário da língua a se tornar mais crítico e eficiente, também, nas suas escolhas lexicais. Outro ponto a ser considerado é a progressão existente nos três itens que compõem a questão. Os comandos "indique", "ordene" e "comente", na ordem em que aparecem, apresentam um aprofundamento reflexivo, do mais superficial ou fácil, até o mais profundo ou complexo. Essa ordenação contribui para a cognição do aluno no que se refere às habilidades pretendidas. Outra atividade que se encontra na obra destinada ao $6^{\circ}$ ano, cujo objetivo demonstra ser o estudo de sinonímia, é a seguinte:

Releia agora as seguintes frases.

I. "Passava horas e horas na praia, com a pindaíba na mão e os peixes fugiam dele como o Diabo da cruz."

II. "Viveram como Deus com os santos."

III. A Mãe-d'Água, com paciência, começou fazendo mais depressa o que ele dissera, mas não vinha na rapidez do corisco".

a) Há muitas formas de expressar as mesmas ideias. Quais palavras do quadro têm o sentido equivalente às expressões em destaque nas frases acima?

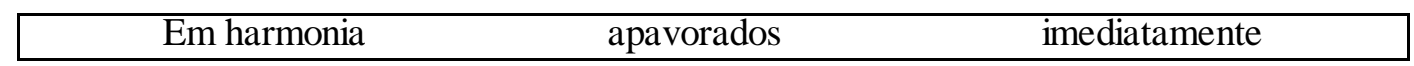

b) Quando usamos as palavras do quadro acima no lugar das expressões populares, que tipo de mudança ocorre na linguagem do texto?

(Para viver juntos, $6^{\circ}$ ano, p. 19)

A questão transcrita é bem-sucedida ao assumir a importância de unidades fraseológicas em uma reflexão linguística, admitindo a perspectiva de que os fraseologismos apresentam um sentido global que se distingue daquele que seria proveniente da soma das palavras lexicais que os compõem. Outro ponto positivo se refere à exploração da idiomaticidade, o que ocorre a partir da discussão acerca da linguagem mais popular, informal. No entanto, no que diz respeito ao trabalho com a sinonímia, a atividade segue a tendência simplória, muito comum aos livros didáticos, de considerar que é possível substituir palavras e expressões por outras equivalentes. Nesse caso, um aspecto que reforça a superficialidade da questão é o fato de, na letra "a", haver a indicação de duas palavras e de uma locução que seriam plenamente substituíveis pelas expressões destacadas nas três frases citadas anteriormente, isto é, ao aluno cabe um esforço intelectual restrito, quase automático. Muito embora a segunda parte da atividade se direcione para a mudança da linguagem informal para a formal, não há discussão efetiva sobre os efeitos de sentido provocados pela suposta mudança, tampouco sobre as escolhas lexicais, as quais não são arbitrárias, o que é bastante evidente nos trechos destacados do texto estudado na unidade. Essas ausências observadas na questão comprometem a sua eficiência em uma perspectiva social de língua. Assim, a fim de 
contribuir para uma reflexão mais aprofundada, aliando o desenvolvimento da competência lexical ao da leitora, sugere-se que a sinonímia seja trabalhada, nesse exercício, em consonância com as sutilezas das escolhas lexicais. Mais uma vez, abaixo, encontra-se uma reformulação da atividade em análise, a qual poderia ser, de modo prático, realizada pelo professor que vier a utilizar tal LDP.

(02) Releia agora as seguintes frases.

IV. "Passava horas e horas na praia, com a pindaíba na mão e os peixes fugiam dele como o Diabo da cruz."

V. "Viveram como Deus com os santos."

VI. A Mãe-d'Água, com paciência, começou fazendo mais depressa o que ele dissera, mas não vinha na rapidez do corisco".

a) Há muitas formas de expressar uma ideia. Explique a pertinência das expressões acima destacadas a partir da noção de que, em um texto, é necessário adequar a sua linguagem aos seus propósitos comunicativos.

b) A fim de adaptar os trechos acima para a linguagem formal, substitua as partes destacadas por palavras ou expressões equivalentes.

Na reformulação, o aluno é levado a refletir sobre a variação linguística, a qual se consolida, dentre outros fatores, na e pela escolha lexical. Nesse sentido, mostra-se relevante o primeiro item, o qual traz à tona a relevância da pertinência do vocabulário de um texto aos seus propósitos comunicativos. Já o segundo, em complementaridade ao primeiro, exige do estudante o esforço intelectual de adaptar os textos para o registro formal, atividade esta que o leva a perceber que, embora sinônimas, certas palavras e expressões servem a contextos distintos. Como se evidenciou por meio dos dois exemplos retirados da obra "Para viver juntos", o LDP, ainda que apresente inadequações às propostas de perspectiva textual que efetivamente viabilizam um ensino harmônico de léxico e de leitura, disponibiliza atividades que podem ser reaproveitadas pelos professores, o que se mostra coerente com a rotina e com o volume de trabalho desses profissionais, os quais, devido a isso, muitas vezes não têm condições de elaborar materiais plenamente autorais.

\section{Considerações finais}

Este trabalho teve como principal objetivo ampliar as reflexões realizadas sobre a interseção dos ensinos de leitura e de léxico, promovendo discussões que visam a um melhor entendimento do modo como as habilidades relacionadas a eles têm sido desenvolvidas em sala de aula a partir do material didático de maior prestígio e utilização no país, o livro didático. Verificou-se que é recorrente o estudo do léxico estar desconectado ao do texto, evidenciando-se, em muitos LDP, apenas nas relações de sinonímia e de antonímia (exercícios de substituição). Já a leitura ainda se revela em atividades que não desenvolvem o senso crítico do aluno, que não contemplam as amarras do texto, que se atêm aos seus aspectos mais superficiais, sem que o aluno precise fazer inferências.

Diante do atestado fato de que os LDP não têm atendido às demandas relacionadas ao léxico e à leitura, bem como da realidade de que esses aspectos são indissociáveis no ensino de línguas, é importante traçar propostas que visem a amenizar tal problemática. Neste artigo, portanto, foram discutidas maneiras mais eficientes de trabalhar a sinonímia, sem desprezar o LDP, mas reformulando as propostas trazidas por ele. Tais reformulações se mostram em sintonia com a concepção de língua enquanto instrumento de 
comunicação mutável, flexível, plástico, que se mostra à disposição dos falantes para a sua expressão. Isso significa que o contexto, o conhecimento de mundo do leitor e as escolhas lexicais do autor passariam a ser tratados holisticamente, bem como os sinônimos seriam vistos sob o ângulo do que os diferencia, e as repetições seriam encaradas, para além de simples erros, como elementos coesivos. Vale dizer que a explanação teórica, a indicação do estado da arte do tema e as instruções acerca das táticas para modificação ou aperfeiçoamento de atividades de LDP que o professor julgar pouco alinhadas aos seus propósitos didáticos, tiveram a intenção de garantir a praticidade, a dialogicidade e a autonomia do docente no processo de ensino-aprendizagem de leitura e de léxicos. Portanto, os principais interesses deste artigo se aliaram ao pensamento crítico, ao trabalho cooperativo, à habilidade e à versatilidade na realização de tarefas, bem como na utilização dos conhecimentos adquiridos para um aprendizado contínuo e autônomo.

\section{REFERÊNCIAS}

ANDRADE, A. D.; SANTOS M. C. V. Gêneros textuais com tratamento do léxico nos livros didáticos de língua portuguesa. In: Anais do XI Encontro do Círculo de Estudos Linguísticos do Sul-CELSUL, Unisul, 2010, p. 468-478.

ANTUNES, I. Aspectos da coesão do texto: uma análise em editoriais jornalísticos. São Paulo: Editora Universitária, 1996. 306 p.

2009. $181 \mathrm{p}$.

Aula de Português: encontro e interação. 8. ed. São Paulo: Parábola Editorial,

Análise de textos: fundamentos e práticas. São Paulo: Parábola Editorial, 2010. $224 \mathrm{p}$.

Território das palavras: estudo do léxico em sala de aula. São Paulo: Parábola Editorial, 2012. 182 p.

AZEREDO, J. C. A quem cabe ensinar a leitura e a escrita? In: Da língua ao discurso: reflexões para o ensino. PAULIUKONIS, M. A. L.; GAVAZZI, S. (Org.). Rio de Janeiro: Lucerna, 2007. p. 30-42.

BERTIN, T.; BORGATTO, A. T.; MARCHEZI, V. Projeto Teláris: Português: $\sigma^{o}$ ano. São Paulo: Ática, 2012. 332 p. . Projeto Teláris: Português: $7^{o}$ ano. São Paulo: Ática, 2012. 320 p. . Projeto Teláris: Português: $8^{o}$ ano. São Paulo: Ática, 2012. 352 p. . Projeto Teláris: Português: $9^{\circ}$ ano. São Paulo: Ática, 2012. 380 p.

BIDERMAN, M. T. C. Condições para aquisição de vocabulário. In: $8^{\circ}$ Intercâmbio de Pesquisas em Linguística Aplicada, 1998, São Paulo. Anais. São Paulo: PUC-SP, 1998, p. 1-10.

BIDERMAN, M. T. C.Dimensões da palavra. n.2. In: Filologia e Linguística portuguesa. São Paulo: UNESP, 1998. p. 81-118.

BIDERMAN, M. T. C. Teoria linguística. São Paulo: Martins Fontes, 2001. 356 p.

BORTONI-RICARDO. S. M. Compreensão de leitura: da palavra ao texto. In: Palavra: Forma e sentido. GUIMARÃES, E; MOLLICA, C. (org.). Campinas: Mercado das Letras, 2007. p. 99-107. 
CAFIERO, D.; COSCARELLI, C. V. Ler e ensinar a ler. In: COSCARELLI, C. V. (Org.). Leituras sobre a leitura: passos e espaços na sala de aula. Belo Horizonte: Veredas, 2013. $191 \mathrm{p}$.

CALÇADA, G. F. Ensino do vocabulário no livro didático. In: Estudos linguísticos XIX. Bauru: Anais de seminário do GEL, 1990, p. 292-301.

CORREIA, M. Produtividade lexical e ensino de língua. In: Língua portuguesa: descrição e ensino. VALENTE, A. C.; PEREIRA, M. T. G. (org.). Rio De Janeiro: UERJ, 2011. p. 223-237.

COSTA, C. L; MARCHETTI, G; SOARES, J. J. B. Para viver juntos: português: ensino fundamental. $6^{\circ}$ ano. 2. ed. São Paulo: Edições SM, 2011. 304 p.

CRUZ, A. F. T. D. Léxico e livro didático: estratégias para o ensino de leitura. 2015. 171 f. Dissertação (Mestrado em Linguística Aplicada) - Programa de Pós-graduação em Estudos Linguísticos, Universidade Federal de Minas Gerais, Belo Horizonte.

CRUZ, A. F. T. D.; MENDES, M. Mudança linguística: do blecaute ao apagão. No prelo.

DELL'ISOLA, R. L. P. O sentido das palavras na interação leitor <-> texto. Belo Horizonte: Faculdade de Letras da UFMG, 2005. 319 p.

DIEB, M. A leitura na sala de aula. In: COSCARELLI, C. V. (Org.). Leituras sobre a leitura: passos e espaços na sala de aula. Belo Horizonte: Veredas, 2013. p. 36-59.

ELIAS, V. M.; KOCH, I. V. Ler e compreender os sentidos do texto. 3. ed. $7^{\text {a }}$ reimp. São Paulo: Contexto, 2012.216 p.

FERRAZ, A. P. "A inovação lexical e a dimensão social da língua". In: SEABRA, M. C. T. C. O. (Org.). O Léxico em estudo. Belo Horizonte: Faculdade de Letras/UFMG, 2006. p. 217-235.

Os neologismos no desenvolvimento da competência lexical. In: HENRIQUES, C. C.; SIMÕES, D. (orgs.). Língua portuguesa, educação \& mudança. Rio de Janeiro: Europa, 2008. p. 146-162.

El desarrollo de la competencia léxica desde el uso de material auténtico en la enseñanza de PLE. In: Actas del IX Congreso Internacional de Linguística General. Valladolid: Universidad de Valladolid. 2011. p. 1846-1859.

KLEIMAN, A. Oficina de leitura: teoria e prática. 4. ed. Campinas: Editora da Universidade Estadual de Campinas, 1996. 156 p.

KOCH, I. G. V. Léxico e progressão referencial. In: Estudos em homenagem ao Professor Doutor Mário Vilela (I e II volumes). Faculdades de Letras da Universidade do Porto, 2005. p. 263-275.

Léxico e progressão textual. In: Investigando a linguagem em uso: estudos em linguística aplicada. GIERING, M. E.; TEIXEIRA, M. (orgs.). Campinas: Editora Unisinos, 2004. p. 45-56.

LEFFA, V. J. Aspectos externos e internos da aquisição lexical. In: LEFFA, V. J. (Org.). As palavras e sua companhia: o léxico na aprendizagem. v.1. Pelotas: Educat, 2000. p. 15-44.

MARCUSHI, L. A. Compreensão de textos: algumas reflexões. In: DIONÍSIO, A. P.; BEZERRA, M A. (orgs.). O livro didático de português: múltiplos olhares. 2. ed. Rio de Janeiro: Lucerna, 2003. p. 46-59. 
PARÂMETROS CURRICULARES NACIONAIS - TERCEIRO E QUARTO CICLOS DO ENSINO FUNDAMENTAL: LÍNGUA PORTUGUESA. Brasilia, Secretaria de educação Fundamental MEC, 2013. 107 p.

PAULIUKONIS, M. A. L. Ensino do léxico: seleção e adequação ao contexto. In: GAVAZZI, S.; PAULIUKONIS, M. A. L. (orgs.). Da língua ao discurso: reflexões para o ensino. Rio de Janeiro: Lucerna, 2007. p. 103-128.

RAMOS, K. A. H. P. Considerações a respeito do livro didático de português. In: XLVIII Seminário do GEL (Grupo de Estudos Linguísticos do Estado de São Paulo), Assis. Estudos Linguísticos XXIX. Assis: UNESP, v. 29. 2000, p. 737-742.

RAMOS, F. B.; VOLMER. L. O livro didático de português (LDP): Variação de gêneros textuais e a formação do leitor. In: SIMPÓSIO INTERNACIONAL DE ESTUDOS DE GÊNEROS TEXTUAIS, Caxias do Sul. Anais. Caxias do Sul, 2009, p. 1-14.

RESENDE, P. S. C. Exploração de capacidade de compreensão: o que os livros didáticos ensinam e o que as provas avaliam? 2012. 123 f. Dissertação (Mestrado em Linguística Aplicada) - Programa de Pós-graduação em Estudos Linguísticos, Universidade Federal de Minas Gerais, Belo Horizonte.

SCAFUTO, S. M. A. O léxico como elo de coesão lexical. In: Revista Universitá, v. 4, Brasilia, p. 1-11, 2007.

TRAVAGLIA, L. C. Para que ensinar teoria gramatical. Rev. Est. Ling., Belo Horizonte, v.10, n.2, p. 135-231, 2002.

TEIXEIRA, D. G. A. Léxico e atividades de categorização no livro didático de língua portuguesa. 2009. 111 f. Dissertação (Mestrado em linguística) - Programa de pósgraduação em Letras, Universidade Federal do Pernambuco, Recife.

Recebido em: 05/10/2015

Aprovado em: 09/04/2016 